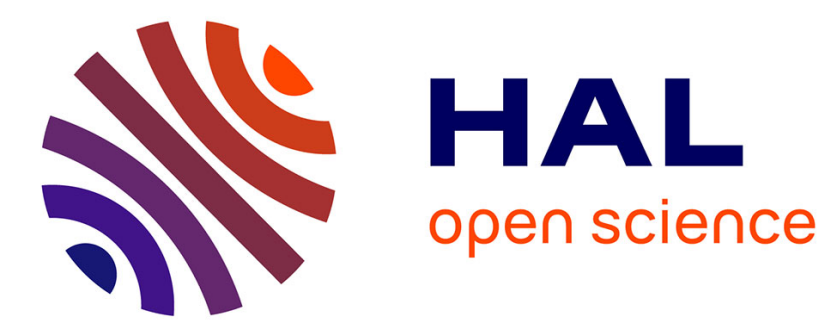

\title{
Supply Chain Scenarios for Logistics Service Providers in the Context of Additive Spare Parts Manufacturing
}

Daniel Pause, Svenja Marek

\section{To cite this version:}

Daniel Pause, Svenja Marek. Supply Chain Scenarios for Logistics Service Providers in the Context of Additive Spare Parts Manufacturing. IFIP International Conference on Advances in Production Management Systems (APMS), Sep 2019, Austin, TX, United States. pp.51-58, 10.1007/978-3-03029996-5_6. hal-02460484

\section{HAL Id: hal-02460484 https://hal.inria.fr/hal-02460484}

Submitted on 30 Jan 2020

HAL is a multi-disciplinary open access archive for the deposit and dissemination of scientific research documents, whether they are published or not. The documents may come from teaching and research institutions in France or abroad, or from public or private research centers.
L'archive ouverte pluridisciplinaire HAL, est destinée au dépôt et à la diffusion de documents scientifiques de niveau recherche, publiés ou non, émanant des établissements d'enseignement et de recherche français ou étrangers, des laboratoires publics ou privés. 


\title{
Supply Chain Scenarios for Logistics Service Providers in the Context of Additive Spare Parts Manufacturing
}

\author{
Daniel Pause, Svenja Marek \\ Institute for Industrial Management (FIR), Aachen, Germany \\ \{daniel.pause, svenja.marek\}@fir.rwth-aachen.de
}

\begin{abstract}
Current supply chain structures in the spare parts logistics are changing profoundly due to the influence of digitalization and additive manufacturing (AM). In particular the Logistics Service Provider (LSP) is influenced by the change, as the physical transport of goods could become redundant due to the digital transmission of production data. This leads to a reduction of the LSP's share in the value chain. Conceptualizing a new role for the LSP for additively manufactured spare parts is necessary. Therefore, five different scenarios are identified in which the LSP serves as a transport carrier, digital distributor, an AM decision maker, a selector of the manufacturer and as an AM service provider.
\end{abstract}

Keywords: Additive / Rapid Manufacturing (AM), Logistics Service Provider (LSP), Spare Parts Management, Spare Parts Logistics, Supply Chain Management

\section{Introduction}

The common value structures in logistics and supply chain management are about to undergo a profound change, mainly driven by technology. 95 percent of all logistics companies surveyed are convinced that digitization will trigger a profound change in logistics processes $[1,2]$. In particular booking platforms, will gain in importance and take on a new mediating position between the client and the Logistics Service Provider (LSP) [3, 4]. In the long term, however, Additive Manufacturing (AM) may have an even greater influence on the reorganization of existing logistics structures. Significant advantages of AM, such as on-demand production of small lot sizes, drive the implementation of the described future scenario [5].

German industry sees high potential for AM in the spare parts industry as an example of Rapid Manufacturing, which has been the result of a study concerning the future of spare parts. The study states that in the next five years, more than 85 percent of spare parts suppliers will apply Rapid Manufacturing to their business and companies which incorporate printing spare parts today will gain a sustainable competitive advantage in the future. [6]

The high potential in the field of Rapid Manufacturing is illustrated by the recently high and dynamic research and development activities which leads to a maturing of the procedure and applications. Regarding publications and patent registrations, Rapid Manufacturing has already gained more importance than Rapid Prototyping [7]. There are several examples of the increasing importance of Additive Manufacturing of spare parts in the industry: General Electric Aviation is printing fuel nozzles for its aircraft engines [8]. Daimler manufactures additively spare parts for trucks and has already over 30 digital models in a "virtual" warehouse. AM is furthermore applied by Siemens in the field of train manufacturing [9]. Siemens stores more than 450 digital models in a "virtual" warehouse, which can be printed on demand [10].

\section{Motivation}

Following the influence of digitization and the resulting possibility to digitally transmit the production data, the physical transport of goods between manufacturer and customer 
could become redundant. The $\mathrm{CAD}^{1}$ file of a spare part would be sent digitally to the place of use and manufactured locally [11]. The reduction or abolition of delivery routes could reduce the LSP's share in the value chain. Consequently the arising question is what the LSP's future market position will look like. For this reason it is necessary to design a new role concept for the LSP in the value chain for additively manufactured spare parts.

From the LSP's viewpoint additional services in the field of after-sales or spare-parts logistics seem especially attractive, as the margin is much higher than in the traditional transport business. After-sales-offers contain value-added-services so that the LSP takes over additional value adding tasks such as stock and demand planning. [12]

As the number of manufacturing service providers increases, the demand for players who can act as intermediaries between end customers and manufacturing service providers increases. Such players can also be described as intermediaries. Spare parts customers benefit from intermediaries who offer a complete supply chain solution with capacity, transport and technology planning. In this context spare parts customers can continue to concentrate on their individual core competencies. [12]

Especially in the context of spare parts, the central challenge is the fast delivery of needed spare parts. Oftentimes, specialized spare parts are not available constantly and an expensive loss of production can be the result. AM can increase the service efficiency and have a positive impact on the logistics costs due to the optimization of spare parts availability.

The morphological box shown in Fig. 1 illustrates the field of observation of the research. The target group encompasses suppliers, Original Equipment Manufacturer (OEM), the LSP and the customers and is referring to capital goods. Part of the logistics field are the intralogistics as well as the logistics across companies. Furthermore, the subsystems storage, warehousing and transport are taken into account. Spare parts are the field of observation and in particular single-items which are critical to the function.

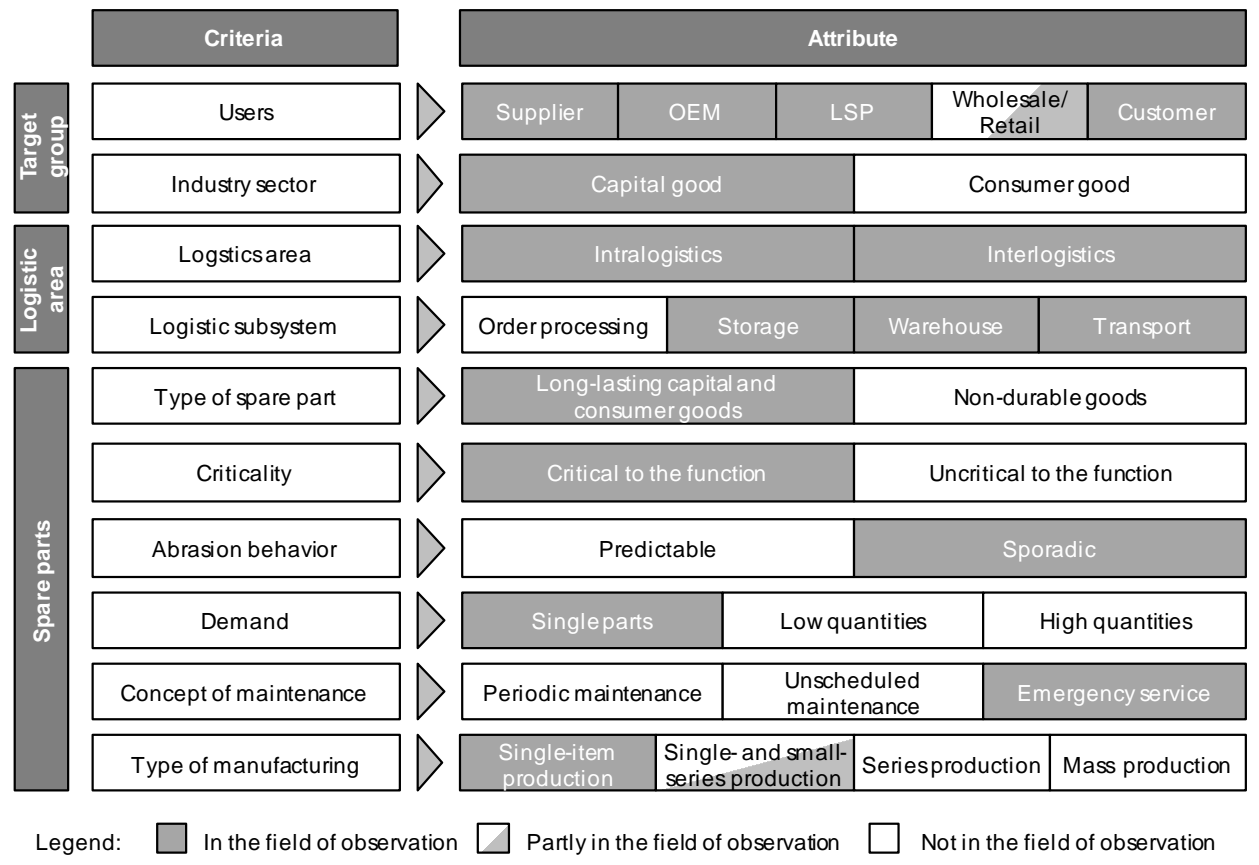

Fig. 1. Field of observation based on a morphological box

\footnotetext{
${ }^{1} \mathrm{CAD}$ : computer-aided design
} 


\section{State of the Art}

The impact of additive spare parts manufacturing in the service portfolio of LSPs has been reviewed in several public articles, which claim its future importance [13,14]. There are several pilot projects of international logistics service companies, such as UPS offering AM services in 29 US states [14]. However, all AM approaches so far resemble a trial and error procedure and do not follow a scientific approach. Therefore an investigation of the importance of the scientific relevance and state of research of the LSP's role in AM is essential.

Huth and Goele [15] investigate the potential of spare parts logistics in the region of Berlin in Germany. Based on an empirical research the importance of spare parts logistics for manufacturing companies is identified. The role of spare parts logistics for the corporate success, the outsourcing potential, the current application as well as challenges in the application are measured.

Barkawi et al. [12] investigate potentials of after-sales-businesses for different sectors. The authors focus on the collaboration of different supply chain actors to achieve an increase of value. There is no application of a typology or empirical research.

Geiger [16] investigates the spare parts industry as a future market for LSP and the current and future role that a LSP can take. Systematic fields of application of LSPs, customer requirements as well as prerequisites for entering new businesses are identified. Therefore an empirical study as well as a typology are applied.

The illustrated research studies analyze the LSP's possible role and market position in the future. However, all the research studies do not consider the impact of AM technologies on the LSP's service portfolio, which will be addressed in this work.

\section{Supply Chain Scenarios for LSPs in the context of Additive Spare Parts Manufacturing}

The equivalent term of the supply chain is often used for the term logistics network [17]. The core task in Supply Chain Management is the economic and demand-oriented connection of sources and sinks, or production sites and customers, through the exchange of material, information and financial flows [18]. Schuh et al. [17] are dividing a supply chain network vertically into four levels: network, company, function and resources. In this study the network level is considered.

In particular, spare parts logistics will be projected to this level, which represents a subarea of supply chain management [15]. According to Huth \& Goele [15] spare parts logistics ensures that the spare parts required for the maintenance and/or repair of plants, equipment and end products are made available to the appropriate consumer in the required quantity, type and quality at the right time and as cost-effectively as possible. Since the influence of AM on spare parts logistics has not yet been sufficiently investigated, possible scenarios in which the logistics service provider shows an involvement in the spare parts service process are presented below. Apart from the basic scenario which characterizes the LSP as a carrier of spare parts there are four other scenarios. The LSP changes its roles in each of the following scenarios. (see Fig. 2) 


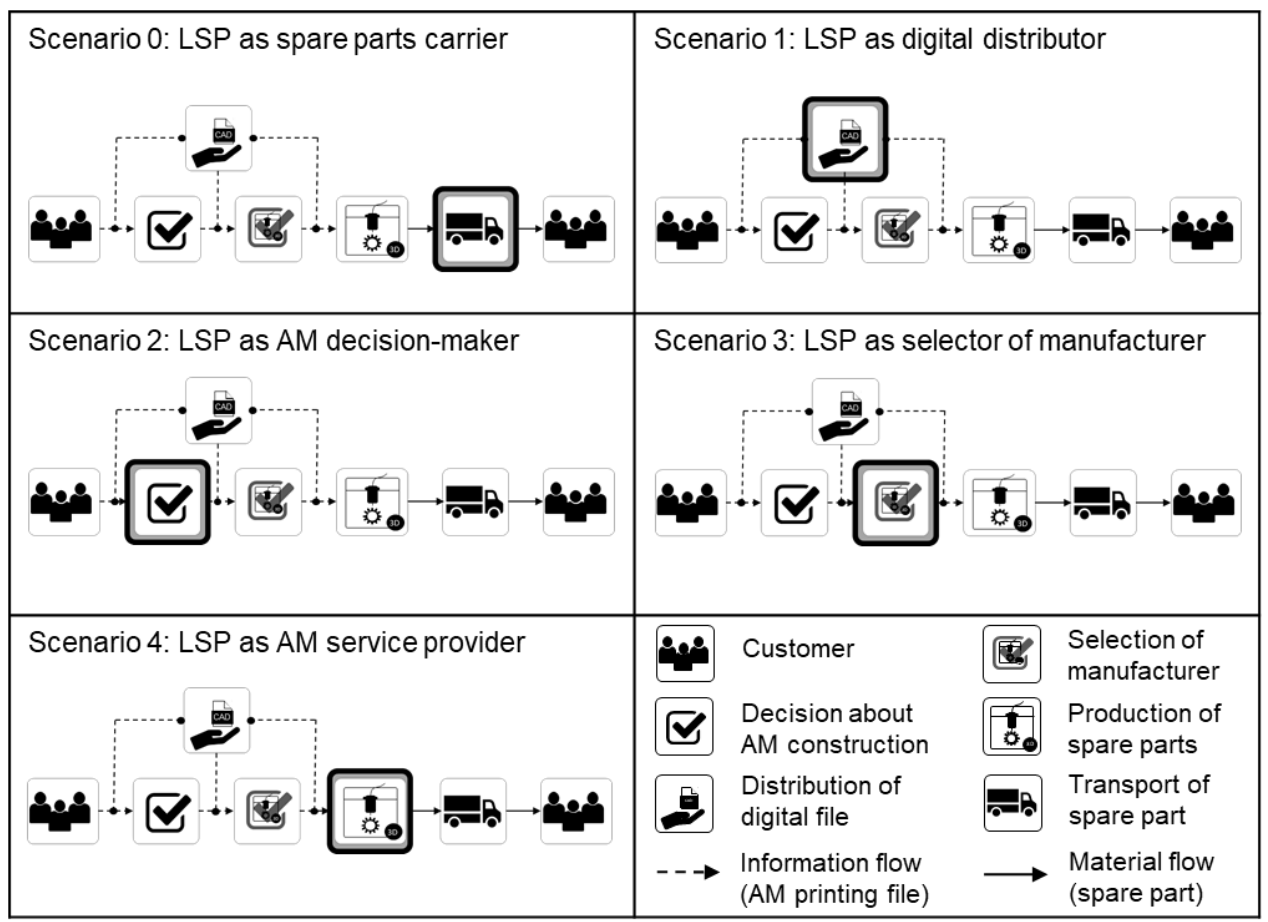

Fig. 2. Scenarios for the LSP in the additive spare parts supply chain

The spare parts supply chain consists of different functional roles, which are necessary to fulfil the additive spare parts service and which the logistics service provider could potentially play. The functional roles comprise the digital distributor (Distribution of digital file), the AM decision maker (Decision about AM construction), the selector of manufacturer (Selection of manufacturer), the manufacturer of additive spare parts (Production of spare parts), and the carrier of spare parts (Transport of spare parts). The spare parts customer (Customer) triggers the process with a spare parts order and then receives the finished spare part. The spare parts customer determines the demand of spare parts and what is required from the suppliers in the sense of delivery time, flexibility and availability. The customer can be a private person or a company. The fast delivery of spare parts can be economically essential for the customer.

In Scenario 0, the LSP functions as a carrier and is responsible for the planning as well as the execution of the transport and delivery orders. The other tasks are performed by other actors. For this purpose, there are various variants: for example the customer could decide for himself whether the part can be produced additively, or the task could be a service offered by the producer. There are also various possibilities in the selection of the additive manufacturer. This could happen individually by the customer but could also be a service provided by a third party. For example, express shipping or emergency logistics are already offered by the LSP. This could also be used in the context of additive spare parts logistics, for example via night express, same day transport, direct travel, direct flight or taxi.

Scenario 1 characterizes the LSP as a digital distributor. The digital distributor is responsible for the safe delivery of construction data, such as CAD data, from the spare parts customer to the AM service provider [19]. If the spare parts customer is not in possession of the construction data he might get in contact with the OEM to get the necessary data. Otherwise the OEM can also represent the spare parts customer in the spare parts supply chain presented above. In order to fulfill the role of digital distributor, extensive know-how in the field of data management and data distribution is necessary in order to ensure a safe, fast and reliable transfer of the CAD data. Moreover, it is required that IP rights are being maintained through new technologies, crypto procedures, privacy management, etc. The 
LSP serves as the first contact person for the AM service provider and the customer. Therefore, it needs to be considered that the LSP ensures the limited availability of the recipient. Whether and to what extent the LSP performs further tasks in this scenario must be decided individually by the LSP. It would be imaginable that the LSP takes over the role as a spare parts carrier.

In Scenario 2 the LSP serves as an AM decision maker and holds knowledge of development and construction of spare parts. The LSP consults the customer regarding potentials of AM related to the development, production and delivery of spare parts and decides if to apply additive or conventional manufacturing to the object of interest. To provide a wellfounded information and decision basis various aspects have to be taken into account. For example, the shape and size of the object are important factors. In addition the economic efficiency and possible potentials that could result from topology and shape optimization must also be taken into account. Beyond that it might be useful to combine this scenario with the previous one. It would also be necessary to decide which actor would carry out the other tasks.

In Scenario 3 the LSP functions as a selector of manufacturer. After the AM data has been developed, the LSP chooses an AM service provider that fits the order. To do this, the LSP must first define the information requirements of the customer and the producer. The LSP takes up the customer's requirements in a systematic approach and compares them with the characteristics of the producers. To do this, the LSP uses a matching algorithm and a defined valuation model. The result is a list with possible producers, which is presented to the customer. Based on this list the customer could choose the producer. The other tasks in the scenario can be performed by different actors. This decision must be made individually based on a business case consideration.

Scenario 4 characterizes the LSP as an AM service provider. The LSP has its own production capacity as well as production and construction skills, which is why in Scenario 4 the initial investment costs are comparatively high. AM is a technology that can theoretically be used anywhere in the world and thus enables customer-oriented production. A LSP, which has several distribution and warehouse locations nationally and globally, has optimal prerequisites for the implementation of 3D printers at their locations. A distinction can be made between a central and a decentral production. In both situations there are specific advantages and disadvantages which should be weighed up individually. The LSP competes with other AM service providers and can be requested directly by the customer or in cooperation with a digital distributor. This is a contract manufacturing of the spare part where the data is delivered by the digital distributor. After the spare part has been manufactured, it is delivered directly from the LSP to the customer. However, the delivery can also be carried out by another logistics service provider. Furthermore, the production of the spare part can be subcontracted or the core aspects, such as redesign, 3D printing, post-processing or quality assurance can be outsourced by the LSP.

The scenarios described above are summarized in the following figure (see Fig. 3). For a structured summary, a morphological box with three characteristics and associated characteristics is used, which summarizes the necessary competencies of the logistics service provider for the respective scenarios. The first descriptive characteristic is the function of the logistics service provider. The logistics service provider can be a service provider (performer), consultant or intermediary. In addition, the necessary professional competence is presented. A distinction is made between competence in handling information transfer, production, design and logistics. In addition, the existence of production capacities is defined. These can belong directly to the logistics service provider itself or the use of outside capacities can be taken up. 


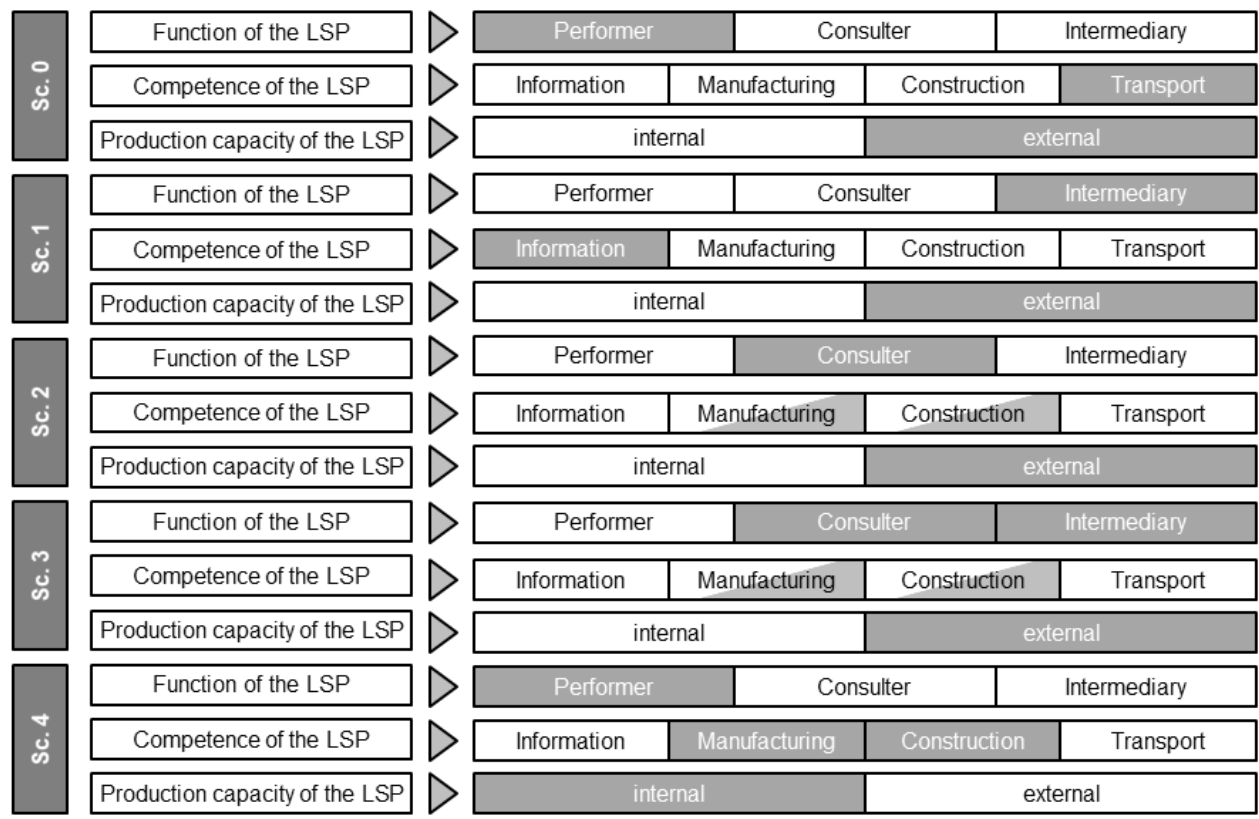

Legend:

In the field of observation

Partly in the field of observation Not in the field of observation

Fig. 3. Overview of the function, competencies and production capacities of logistics service providers per supply chain scenario

\section{Conclusion and further research}

Based on the changing role of the LSP due to the digitalization, five scenarios describing the role of LSP have been developed to identify the LSP's future market position. For each role, different requirements are needed and a different base of knowledge is necessary. Thus, the identification of the optimal role of a LSP depends on his individual characteristics. Further research is furthermore needed in the areas of technology, property rights and business models. Concerning the technology, it is essential to decrease the process times of AM so that on-demand manufacturing can be realized. In terms of property rights, the ownership rights of the CAD files are yet to be determined. The digital interfaces between OEM, digital distributor and AM service provider need to be determined exactly. In addition business models have to be identified in order to quantify the value created for the LSP and enable a well-founded decision to be made.

Acknowledgements. This research and development project 3Dsupply is funded by the German Federal Ministry of Education and Research (BMBF) within the "Innovations for Tomorrow's Production, Services, and Work" Program (funding number 02K16C162) and implemented by the Project Management Agency Karlsruhe (PTKA). The author is responsible for the content of this publication.

SPONSORED BY THE

Federal Ministry

of Education

and Research 


\section{References}

1. Kayikci, Y.: Sustainability impact of digitization in logistics. Procedia Manufacturing (2018). doi: 10.1016/j.promfg.2018.02.184

2. Bundesvereinigung Logistik: Digitalisation in Logistics. https://www.bvl.de/en/positionpaper-digitisation (2017). Accessed 8 August 2019

3. Baums, A.: Industrie 4.0 - politische Aspekte. http://plattform-maerkte.de/wp-content/uploads/2015/03/Industrie-4_0-Feb-2015_Blog.pdf (2015). Accessed 8 February 2019

4. Marwyk, K. van, Treppte, S.: Digital business models in logistics - Results. Roland Berger, München (2016). Accessed 5 August 2018

5. Gebhardt, A.: Additive Fertigungsverfahren. Additive Manufacturing und 3D-Drucken für Prototyping - Tooling - Produktion, 5th edn. Hanser, München (2016)

6. Geissbauer, R., Wunderlin, J.: The future of spare parts is 3D. A look at the challenges and opportunities of 3D printing. PwC Strategy\& (2017)

7. TAB: Technikfolgenabschätzung (TA). Additive Fertigungsverfahren (3-D-Druck). TAB-Arbeitsbericht Nr. 175. Büro für Technikfolgen-Abschätzung beim Deutschen Bundestag (TAB), Berlin. https://www.dgm.de/fileadmin/DGM/Archiv/PrintMedien/Positionspapiere/2017-09-06-Technikfolgeabschaetzung-Additive-Fertigung.pdf (2017)

8. Heinze-Wallmeyer, S.: GE Aviation nutzt additive Fertigung zur Herstellung von Flugzeugturbinen. https://www.3d-grenzenlos.de/magazin/kurznachrichten/ge-aviation-3d-druck-von-flugzeugturbinen-27230923/ (2017)

9. Pankow, G.: Daimler druckt erstes Lkw-Ersatzteil aus Metall. https://www.produktion.de/nachrichten/unternehmen-maerkte/daimler-druckt-erstes-lkw-ersatzteil-ausmetall-112.html (2017)

10. Breuer, H.: A Print-on-demand Manufacturing Plant. https://www.siemens.com/innovation/en/home/pictures-of-the-future/industry-and-automation/additive-manufacturing-spare-parts-for-the-rail-industry.html (2016). Accessed 28 March 2018

11. Thomas, O.e.a.: Supply Chain 4.0: Revolution in der Logistik durch 3D-Druck. IM+io Fachzeitschrift für Innovation, Organisation und Management(März 2016), 58-63 (2016)

12. Barkawi, K., Baader, A., Montanus, S.: Erfolgreich mit After Sales Services. Geschäftsstrategien für Servicemanagement und Ersatzteillogistik. Springer-Verlag Berlin Heidelberg, Berlin, Heidelberg (2006)

13. Scott, C.: FedEx Introduces New 3D Printing Services with FedEx Forward Depots. https://3dprint.com/201472/fedex-3d-printing-forward-depots/ (2018)

14. Ward, J.: Warum UPS glaubt, dass 3D-Drucker die Logistikkette verändern werden. https://news.sap.com/germany/2016/05/warum-ups-glaubt-dass-3d-drucker-die-logistikkette-verandern-werden/ (2016)

15. Huth, M., Goele, H.: Potenzial der Ersatzteillogistik von produzierenden Unternehmen in der Region Berlin/Brandenburg (2013)

16. Geiger, R.: Schlussbericht zum Forschungsvorhaben ET-LDL. IPRI - International Performance Research Institute, Stuttgart (2012)

17. Schuh, G., Stich, V. (eds.): Logistikmanagement. Handbuch Produktion und Management 6, 2nd edn. VDI-Buch, vol. 6. Springer, Berlin [u. a.] (2013)

18. Stadtler, H., Kilger, C., Meyr, H. (eds.): Supply chain management and advanced planning. Concepts, models, software, and case studies, 5th edn. Springer texts in business and economics. Springer, Heidelberg, New York, Dordrecht, London (2015)

19. Business Dictionary: Original Equipment Manufacturer (OEM). http://www.businessdictionary.com/definition/original-equipment-manufacturer-OEM.html (2018). Accessed 30 January 2019 